\title{
Current taxonomy of phages infecting lactic acid bacteria
}

\author{
Jennifer Mahony ${ }^{1 *}$ and Douwe van Sinderen ${ }^{1,2 *}$ \\ 1 Department of Microbiology, University College Cork, Cork, Ireland \\ ${ }^{2}$ Alimentary Pharmabiotic Centre, Biosciences Institute, University College Cork, Cork, Ireland
}

\section{Edited by:}

Akio Adachi, The University of Tokushima Graduate School, Japan

\section{Reviewed by:}

Akio Adachi, The University of

Tokushima Graduate School, Japan Christian Cambillau, Aix Marseille

University, France

*Correspondence:

Jennifer Mahony, Department of

Microbiology, University College

Cork, Food Science and Technology

Building, Cork, Ireland

e-mail: j.mahony@ucc.ie

Douwe van Sinderen, Biosciences

Institute, University College

Cork, Western Road, Room 4.06,

Cork, Ireland

e-mail:d.vansinderen@ucc.ie
Phages infecting lactic acid bacteria have been the focus of significant research attention over the past three decades. Through the isolation and characterization of hundreds of phage isolates, it has been possible to classify phages of the dairy starter and adjunct bacteria Lactococus lactis, Streptococcus thermophilus, Leuconostoc spp., and Lactobacillus spp. Among these, phages of L. lactis have been most thoroughly scrutinized and serve as an excellent model system to address issues that arise when attempting taxonomic classification of phages infecting other $L A B$ species. Here, we present an overview of the current taxonomy of phages infecting $L A B$ genera of industrial significance, the methods employed in these taxonomic efforts and how these may be employed for the taxonomy of phages of currently underrepresented and emerging phage species.

Keywords: Lactococcus, Streptococcus, Lactobacillus, dairy, food fermentation, genetics

\section{INTRODUCTION}

The lactic acid bacteria (LAB) are a heterogeneous group of Gram positive, non-spore-forming bacteria with a rod-shaped or coccoid morphology. As their name suggests, lactic acid is the predominant end-product when LAB engage in hexose fermentation, and it is due to the pre-servative and palatable properties of lactic acid that has for many centuries rendered this group of bacteria applicable in food and feed fermentations, in particular for the production of dairy products. Strains of Lactococcus lactis and Streptococcus thermophilus are the most intensely employed starter bacteria in the dairy fermentation industry globally (Deveau et al., 2006), while strains of Lactobacillus spp. and Leuconostoc spp. are widely used as adjuncts in such processes (Nieto-Arribas et al., 2010). Furthermore, in vegetable fermentations, ecological studies have reported the complex and evolving microbial landscape with strains of Lactobacillus, Pediococcus, Leuconostoc and Weisella spp. implicated at various stages of the fermentation (Lu et al., 2003, 2012). However, as with most living organisms, LAB are susceptible to viral infection by (bacterio) phages, which may impact on the quality, flavor and texture of the final product. The application of these bacteria in modern fermentation processes involves intensive production and throughput, thereby increasing the risk of bacteriophage infection. Phages are particularly problematic in fermentation systems that repeatedly use the same cultures or culture mixes/rotations as phages are known to persist in the processing environs until a suitable host is available to infect. Consequently, phages of LAB have enjoyed significant attention, particularly over the past three decades. All LAB-infecting phages belong Caudovirales order and most of them to the Siphoviridae family that possess long non-contractile tails and isometric or prolate capsids (Mahony et al., 2012a). Additionally, phages with short non-contractile tails (Podoviridae) and those displaying long contractile tails (Myoviridae) have also been described for some LAB genera (Chibani-Chennoufi et al., 2004; Chopin et al., 2007; Deasy et al., 2011). Undoubtedly, the most intensely researched LAB-infecting phages are those of the dairy starter bacteria L. lactis and S. thermophilus (Neve et al., 1998; Lucchini et al., 1999; Quiberoni et al., 2000; Brussow and Desiere, 2001; Proux et al., 2002; Mahony et al., 2006; Guglielmotti et al., 2009; Rousseau and Moineau, 2009; Collins et al., 2013). In recent years, genome sequencing technologies have improved and diversified drastically, and this has probably been the single greatest driving force behind the acquisition of current data regarding LAB-infecting phage biodiversity, taxonomy and evolution. Current phage taxonomic efforts significantly depend on comparative genomic analysis and derived information. Phage taxonomy is a contentious issue, yet a highly important one since such classifications are core to the development of detection tools and prevention and control measures. Here, we will review the changing face of LAB phage taxonomy, the major advances to date and how such taxonomic efforts may influence future efforts at minimizing the risk of phage infection.

\section{LACTOCOCCAL PHAGES}

Phages that infect host strains with resident prophages and/or phage-resistance systems are subject to significant genome rearrangements, which appears to be a major evolutionary driving force among such phages (Labrie and Moineau, 2007). Therefore, it is of great significance that the genome sequences of a number of lactococcal strains and their resident prophages have become available to understand the dynamic processes that may lead to such genome rearrangements (Chopin et al., 2001; Ventura et al., 2007; Wegmann et al., 2007; Siezen et al., 2010; Ainsworth 
et al., 2013; Du et al., 2013). L. lactis strains employed in the dairy industry belong to one of two subspecies, namely L. lactis ssp. lactis or L. lactis ssp. cremoris. While lactococcal strain diversity may be limited, their infecting phages have proven their genomic elasticity and evolutionary capabilities in order to survive and evade hygiene measures, processing conditions and host-encoded phage-resistance mechanisms (McGrath et al., 1999; Scaltriti et al., 2010; Samson et al., 2013). To a large degree, this co-evolution, coupled to the intensity of production, has supported the ever-increasing genetic diversity of these phages as we currently recognize and classify them.

Phages of L. lactis were first classified in 1984 into four groups based on morphology, serological reactions and DNADNA hybridization of 25 phages (Jarvis, 1984). This study was the basis of further classifications of lactococcal phages resulting in the identification of dominant species in isolation studies and furthermore the identification of rarely encountered and emerging species (Prevots et al., 1990).

In 1991, this classification was updated and 12 species were identified based on DNA homology and morphology (Jarvis et al., 1991). The virion morphologies were identified as belonging to one of two families i.e., Siphoviridae and Podoviridae. In 2002, the lactococcal phage BK5-t was proven to be a member of the polythetic P335 species, which has both lytic and temperate members (Labrie and Moineau, 2002), thus reducing the number of lactococcal phage species to eleven.

Most recently, in 2006, Deveau and colleagues reassessed existing phage isolates of $L$. lactis and reduced the number of currently existing lactococcal phage species to ten (Deveau et al., 2006). This re-classification highlighted the extinction of the P107 species and the amalgamation of BK5-t, 1483 and T187 in the P335 species (Deveau et al., 2006). Furthermore, it also highlighted the emergence of new species, such as the Q54 and 1706 species, which were previously unknown or unclassified (Deveau et al., 2006). Over the past decade, representative members of the rare and emerging lactococcal phage species, 949 (Samson and Moineau, 2010), P087 (Villion et al., 2009), P034 (Kotsonis et al., 2008), Q54 (Fortier et al., 2006), 1358 (Dupuis and Moineau, 2010), KSY1 (Chopin et al., 2007) and 1706 species (Garneau et al., 2008), have been sequenced and providing essential information to corroborate this classification scheme.

The above taxonomic studies have all compounded the necessity of combining taxonomic methods (including electron microscopy, DNA-DNA hybridizations/genome sequencing) that complement each other and provide an effective means for grouping phages (Jarvis, 1984; Jarvis et al., 1991; Deveau et al., 2006). In 1990, Prevots and colleagues identified that the virulent 936 species dominated their collection of 101 phage isolates (Prevots et al., 1990) and from information gathered over the ensuing 23 years, this dominance has been retained (Deveau et al., 2006; Rousseau and Moineau, 2009; Castro-Nallar et al., 2012; Murphy et al., 2013). The genome architecture and content of the 936 phages is highly conserved and the success of this species may be attributed to the limited number of strains available to the dairy industry, permitting their propagation and evolution (Mahony et al., 2012b). The P335 phage species is currently the second most frequently isolated species in the dairy industry and this represents a genetically diverse group of phages that may be lytic or temperate (Mahony et al., 2013). Correlating with their industrial significance, the 936 and P335 species phages also dominate in terms of fundamental research pertaining to their genomics and phage-host interactions and serve as models for phages of a variety of Gram positive bacterial hosts (Veesler et al., 2012; Bebeacua et al., 2013; Collins et al., 2013). To date, in excess of 70 lactococcal phage genomes have been sequenced to completion with approximately $70 \%$ of these belonging to the 936 species according to the EMBL-EBI website at the time of writing (www. ebi.ac.uk/genomes/phage.html) (Table 1). Given the lack of complexity of most lactococcal starter cultures, it is not surprising that these species continue to dominate and evolve, however, there are ample possibilities for genetic rearrangements and development of novel species as has been observed in the case of the Q54 species (Fortier et al., 2006). The emergence of such novel species highlights the necessity of regular revisions of the taxonomy of these phages. Furthermore, while the small, isometric-headed phages are the most abundant morphotype of lactococcal phages, the observation of lactococcal siphophages with unusually long tails (949 species), or Podoviridae with decorated capsid structures (KSY1), indicates that morphological assessment remains a useful tool in the taxonomic characterization of such phages as a complement to genotyping.

\section{S. thermophilus PHAGES}

In contrast to the phages of L. lactis, all phages infecting $S$. thermophilus display a similar morphology with long, non-contractile tails (typically more than $200 \mathrm{~nm}$ in length) and isometric capsid structures, thus belonging to the Siphoviridae family (Brussow et al., 1994; Bruttin et al., 1997; Levesque et al., 2005; Guglielmotti et al., 2009; Zinno et al., 2010; Mills et al., 2011). Therefore, electron microscopy and associated morphological analysis provides little scope for differentiation between these phages, thus necessitating the application of other methods of discernment.

In 1994, host range and serological reaction analysis of 81 phages infecting $S$. thermophilus directed the first significant classification of these phages into four classes (Brussow et al., 1994). Only a few years later in 1997, a refinement of this classification was determined through the combined application of DNA restriction profiling, structural protein profiling and host range analysis defined that these phages should be classified into two major groups (Le Marrec et al., 1997). These groups were accordingly named the cos (cohesive ends) and pac (headful packaging method) groups, in congruence with their mode of DNA packaging. This taxonomic system was upheld until the recent isolation of phage 5093, which infects the Mozzarella starter strain CSK939 (Mills et al., 2011). The genome of this phage was sequenced and revealed a novel genotype among $S$. thermophilus phages. It possesses greater homology to non-dairy streptococcal prophage sequences than to the genomes of sequenced S. thermophilus phages. This singular phage represents the newest addition to the lactic streptococcal phage taxonomic grouping system and, as yet, remains the only known member of this third species of $S$. thermophilus phages (Table 1). Furthermore, morphological analysis of this phage revealed globular structures at the tail tip region, a novel feature among lactic streptococcal 
Table 1 | Current taxonomy of LAB phages with sequenced members.

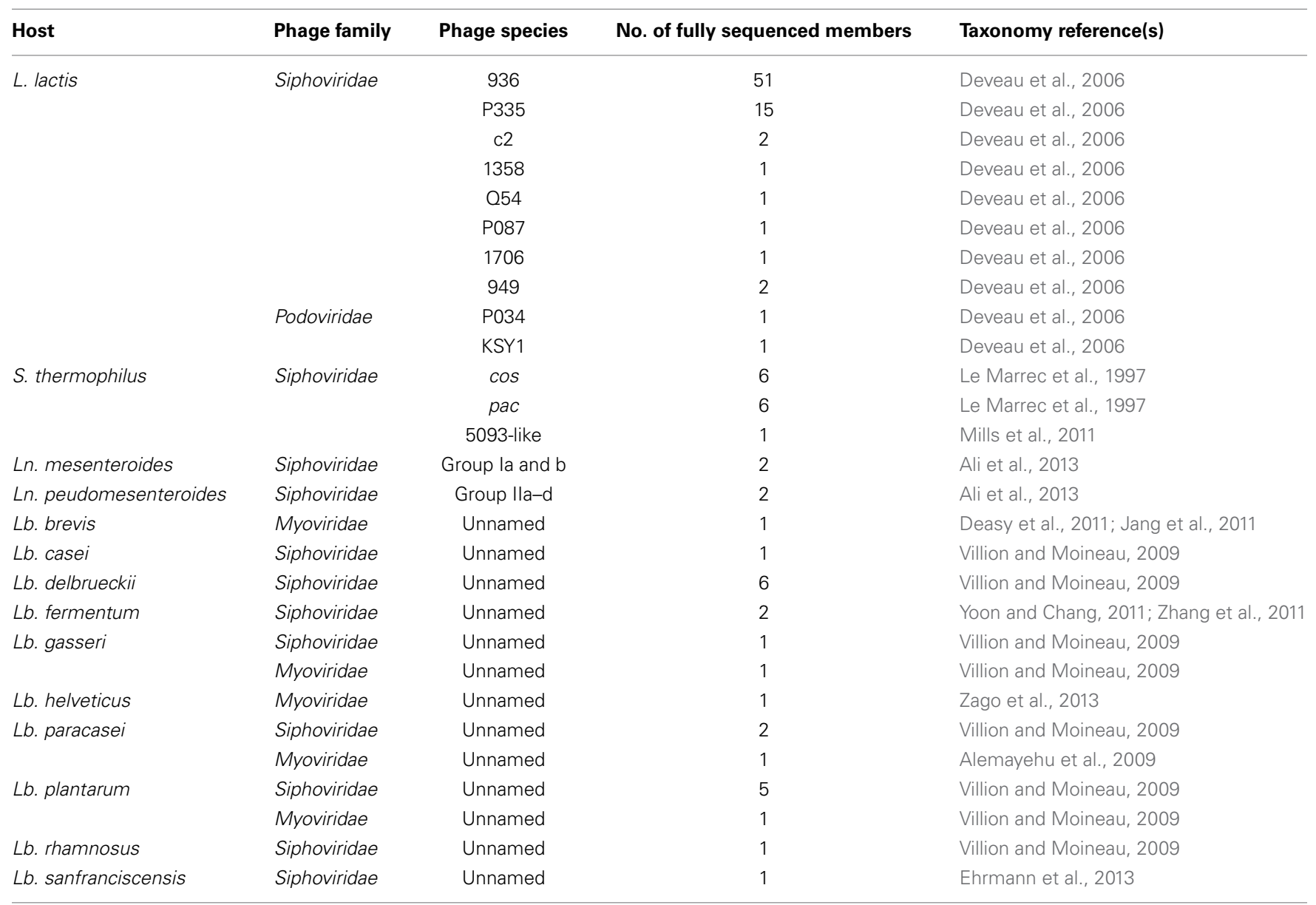

phages, again reinforcing the application of morphological assessment of phage isolates in parallel with other characterization tools.

\section{Leuconostoc PHAGES}

Leuconostoc spp. are part of undefined composite starter mixes of many semi-hard cheeses and are required for aroma and flavor formation in such cheeses (Cogan and Jordan, 1994). Phages of Leuconostoc spp. have received growing and deserved attention in recent years in terms of phage isolation studies and genomic analysis pertaining to vegetable and dairy fermentations (Sutherland et al., 1994; Gindreau et al., 1997; Greer et al., 2007; Lu et al., 2010; Kleppen et al., 2012; Ali et al., 2013; Kot et al., 2013). With respect to those infecting dairy starter and adjunct strains of Leuconostoc mesenteroides and pseudomesenteroides, the most significant taxonomic classification has been provided this year following the analysis of 83 phages by host range, morphology and DNA homology (Ali et al., 2013). This resulted in the identification of species-specific groups capable of infecting one species of Leuconostoc (Table 1). The phages were primarily grouped into two major classes based on their non-overlapping host ranges, I and II (i.e., those capable of infecting either $L n$. mesenteroides or Ln. pseudomesenteroides strains). All phages were observed to possess long non-contractile tails and isometric capsids, consistent with the features of Siphoviridae phages but with distinct baseplate appendages at their tail tip regions. In the case of $L n$. mesenteroides (group I), one dominant species of phages with globular appendages ( 15 of 16 phages assessed) classified as species Ia, while a second species Ib is represented by a single isolate that did not display the globular appendages in its baseplate, but was shown to contain extended Y-shaped appendages (Ali et al., 2013). Phages capable of infecting Ln. pseudomesenteroides (group II) are grouped into four sub-groups and all present with a smaller baseplate structure than their Ln. mesenteroidesinfecting counterparts $(25 \mathrm{~nm}$ vs. $40 \mathrm{~nm})$. Phages possessing a distinct collar structure below the phage head were classified as group IIa, while those without a collar were termed members of group IIb. A third group, IIc, is composed of isolates presenting with a "fluffy" baseplate appendage while the fourth group, IId, contains members that display unusual striations in the phage tail (Ali et al., 2013). In contrast to Ln. mesenteroides and pseudomesenteroides, phages infecting Leuconostoc lactis are rarely reported, representing a major knowledge gap in terms of the overall taxonomy of dairy Leuconostoc phages (Johansen and Kibenich, 1992), however, this underrepresentation may be due to the relatively low levels of usage of strains of this species in dairy 
fermentations (Zamfir et al., 2006). The morphological diversity of phages infecting Leuconostoc species is quite striking given the limited number of strains that are available in the dairy setting. Considering the important role of Leuconostoc strains in flavor and aroma development in many fermented dairy products, this may represent an interesting and emerging area of LAB phage research. The isolation and characterization of further phages and of the dominant species as well as those of Ln. lactis would permit the development of further classification schemes and increasingly sophisticated detection tools for Leuconostoc phages, perhaps allowing a correlation to be made between phage prevalence and flavor development (or lack/reduction thereof), thus revealing the exact role of Leuconostoc strains within a given fermentation.

\section{Lactobacillus PHAGES}

Lactobacillus species are widely used as starter and adjunct cultures for certain food fermentations including the production of yoghurt, cheese, sauerkraut, pickles, and, in conjunction with yeasts, sourdough (Lu et al., 2003; Foschino et al., 2005). Some are used in the dairy industry for their purported probiotic effects (Felis and Dellaglio, 2007). In addition to these food fermentation uses of lactobacilli, some species are associated with food spoilage, e.g., Lactobacillus casei and Lactobacillus brevis are common beer spoilers (Asano et al., 2007). Lactobacillus phages belonging to the families Siphoviridae andMyoviridae have been isolated, while only a single Lactobacillus phage described thus far belongs to the Podoviridae family (Ackermann, 2007; Villion and Moineau, 2009). There is a relative paucity of genomic information regarding phages infecting members of this large and diverse genus, and there is limited taxonomic data regarding these phages (Mahony et al., 2012a). There are over distinct 100 species recognized within the Lactobacillus genus and with such host heterogeneity, it seems unsurprising that phages infecting species of this genus are equally complex and difficult to classify (Claesson et al., 2007). Currently, Lactobacillus phages are primarily classified based on the host species and subsequently into morphological or host range specific groups for a second tier of classification (For an extensive review of these phages, see Villion and Moineau, 2009). To date, the phage genomes of 24 Lactobacillus phages have been fully sequenced (http://www.ebi.ac.uk/genomes/phage.html) and their genetic complexity is clear with genome sizes ranging from $\sim 31-42 \mathrm{~kb}$. It is possible that with increased genome sequence data, identification of taxonomic groups for this diverse genus may be possible. Lactobacillus phages also exhibit morphological diversity and this characteristic may thus be used in their differentiation and taxonomy.

\section{CURRENT LIMITATIONS AND FUTURE PERSPECTIVES}

Taxonomy of LAB-infecting phages has been the cornerstone of the development of detection and control tools, particularly pertaining to dairy fermentations. For example, several multiplex PCR systems have been established for the detection of lactococcal, S. thermophiles, and Leuconostoc phages (Labrie and Moineau, 2000; Del Rio et al., 2007, 2008; Ali et al., 2013). Such systems are essential to fermentation industries which rely on rapid identification of potentially problematic phages in order to limit phage proliferation within a plant. The practical relevance of phage taxonomy by far outweighs the apparent redundancy of repeated phage isolation, characterization and genomics studies as novel genetic elements, emerging phage species and evolving genome sequences continue to emerge. The vast information that currently exists for lactococcal phages has provided a solid basis for classification phages of LAB and other Gram positive bacteria. This data is based on more than three decades of isolation and characterization studies and genome sequencing efforts and have compounded the need for continual monitoring of phage populations. The loss of certain species (as single phage isolates may represent an entire species) and the identification of emerging and evolving phages present a significant challenge to phage taxonomy. With the exception of the Felix d'Herelle reference center for bacterial viruses in Canada, the general lack of centralized phage collection centers or the low uptake on requests for deposition of phage isolates in such collection centers is another issue that limits phage preservation and some phage isolates/species become obsolete if phage stocks are not maintained. Added to this is the lack of uniformity of classification methods. Classical studies relied upon serotyping and DNA-DNA hybridizations, which are time-consuming and not entirely discerning. In contrast, modern methodologies are becoming more reliant on genome sequencing, which has been possible through significant advances in sequencing technologies and throughput (Ronaghi et al., 1998; Eid et al., 2009; Meyer and Kircher, 2010). These advances together with the reduced cost of sequencing will be central to improving our knowledge of complex phage taxonomy groups, such as those represented by phages of the lactobacilli and those of underrepresented genera, including Weisella, Oenococcus, non-dairy lactococci, and Leuconostoc spp. It is evident that combinatorial strategies in phage taxonomy are still as useful today as they were in the past. Genomics combined with microscopic analysis is the current standard approach toward the classification of LAB phages with a decreased need for serotyping and exhaustive hybridization studies. One of the first attempts at unifying phage taxonomy was in 2002 by selecting a single structural protein (capsid or tail) as a phylogenetic marker and through this effort, Siphoviridae phages were classified into four groups (Proux et al., 2002). Following this, more sophisticated proteomic trees using overall proteomic data have been developed as a genome-based strategy for classifying phages. In 2002, the first phage proteomic tree of 105 phages was constructed. In this study, the Siphoviridae LAB-infecting phages clustered into one group of the proteomic tree, which may be sub-divided into the monophyletic taxonomic groups: sk1-like, TP901-1-like, Sfi21like and the $\lambda$-like phages (Rohwer and Edwards, 2002). The Siphoviridae phages displayed most heterogeneity, while phages belonging to the remaining taxonomic groups (e.g., Myoviridae and Podoviridae) clustered into neat groups. This system places the LAB-infecting phages as part of the broader community of sequenced phages and such classification schemes are essential to understanding the overall relatedness and evolution of phages. In more recent years, this system has been expanded upon for Myoviridae and Podoviridae phages (Lavigne et al., 2006, 2009) and has endorsed the application of proteomics as a classification tool. 
It is likely that LAB phage research will continue to focus on those phages that infect industrially significant genera as have been described above. It is also evident that the taxonomy of these phages requires regular review as the lessons learned from lactococcal phage taxonomy highlight the adaptive nature of phages in response to selective pressures in the industrial setting or the availability of alternative hosts (Fortier et al., 2006; Garneau et al., 2008). Therefore, phage taxonomy should be considered a fluid process that reflects the dynamic industrial environment which phages inhabit.

\section{ACKNOWLEDGMENTS}

Douwe van Sinderen is the recipient of a Science Foundation Ireland (SFI) Principal Investigator award (Ref. No. 08/IN.1/B1909).

\section{REFERENCES}

Ackermann, H. W. (2007). 5500 Phages examined in the electron microscope. Arch. Virol. 152, 227-243. doi: 10.1007/s00705-006-0849-1

Ainsworth, S., Zomer, A., De Jager, V., Bottacini, F., Van Hijum, S. A., Mahony, J., et al. (2013). Complete genome of Lactococcus lactis subsp. cremoris UC509.9, host for a model lactococcal P335 bacteriophage. Genome Announc. 1. doi: 10.1128/genomeA.00119-12

Alemayehu, D., Ross, R. P., O’Sullivan, O., Coffey, A., Stanton, C., Fitzgerald, G. F., et al. (2009). Genome of a virulent bacteriophage Lb338-1 that lyses the probiotic Lactobacillus paracasei cheese strain. Gene 448, 29-39. doi: 10.1016/j.gene.2009.08.008

Ali, Y., Kot, W., Atamer, Z., Hinrichs, J., Vogensen, F. K., Heller, K. J., et al. (2013). Classification of lytic bacteriophages attacking dairy Leuconostoc starter strains. Appl. Environ. Microbiol. 79, 3628-3636. doi: 10.1128/AEM.00076-13

Asano, S., Suzuki, K., Iijima, K., Motoyama, Y., Kuriyama, H., and Kitagawa, Y. (2007). Effects of morphological changes in beer-spoilage lactic acid bacteria on membrane filtration in breweries. J. Biosci. Bioeng. 104, 334-338. doi: 10.1263/jbb.104.334

Bebeacua, C., Tremblay, D., Farenc, C., Chapot-Chartier, M. P., Sadovskaya, I., Van Heel, M., et al. (2013). Structure, adsorption to host, and infection mechanism of virulent lactococcal phage p2. J. Virol. 87, 12302-12312. doi: 10.1128/JVI.02033-13

Brussow, H., and Desiere, F. (2001). Comparative phage genomics and the evolution of Siphoviridae: insights from dairy phages. Mol. Microbiol. 39, 213-222. doi: 10.1046/j.1365-2958.2001.02228.x

Brussow, H., Fremont, M., Bruttin, A., Sidoti, J., Constable, A., and Fryder, V. (1994). Detection and classification of Streptococcus thermophilus bacteriophages isolated from industrial milk fermentation. Appl. Environ. Microbiol. 60, 4537-4543.

Bruttin, A., Desiere, F., D’Amico, N., Guerin, J. P., Sidoti, J., Huni, B., et al. (1997). Molecular ecology of Streptococcus thermophilus bacteriophage infections in a cheese factory. Appl. Environ. Microbiol. 63, 3144-3150.

Castro-Nallar, E., Chen, H. L., Gladman, S., Moore, S. C., Seemann, T., Powell, I. B., et al. (2012). Population genomics and phylogeography of an Australian dairy factory derived lytic bacteriophage. Genome Biol. Evol. 4, 382-393. doi: 10.1093/gbe/evs017

Chibani-Chennoufi, S., Dillmann, M. L., Marvin-Guy, L., Rami-Shojaei, S., and Brussow, H. (2004). Lactobacillus plantarum bacteriophage LP65: a new member of the SPO1-like genus of the family Myoviridae. J. Bacteriol. 186, 7069-7083. doi: 10.1128/JB.186.21.7069-7083.2004

Chopin, A., Bolotin, A., Sorokin, A., Ehrlich, S. D., and Chopin, M. (2001). Analysis of six prophages in Lactococcus lactis IL1403: different genetic structure of temperate and virulent phage populations. Nucleic Acids Res. 29, 644-651. doi: 10.1093/nar/29.3.644

Chopin, A., Deveau, H., Ehrlich, S. D., Moineau, S., and Chopin, M. C. (2007). KSY1, a lactococcal phage with a T7-like transcription. Virology 365, 1-9. doi: 10.1016/j.virol.2007.03.044

Claesson, M. J., Van Sinderen, D., and O’Toole, P. W. (2007). The genus Lactobacillus-a genomic basis for understanding its diversity. FEMS Microbiol. Lett. 269, 22-28. doi: 10.1111/j.1574-6968.2006.00596.x
Cogan, T. M., and Jordan, K. N. (1994). Metabolism of Leuconostoc Bacteria. J. Dairy Sci. 77, 2704-2717. doi: 10.3168/jds.S0022-0302(94)77213-1

Collins, B., Bebeacua, C., Mahony, J., Blangy, S., Douillard, F. P., Veesler, D., et al. (2013). Structure and functional analysis of the host recognition device of lactococcal phage Tuc2009. J. Virol. 87, 8429-8440. doi: 10.1128/JVI.00907-13

Deasy, T., Mahony, J., Neve, H., Heller, K. J., and Van Sinderen, D. (2011). Isolation of a virulent Lactobacillus brevis phage and its application in the control of beer spoilage. J. Food Prot. 74, 2157-2161. doi: 10.4315/0362-028X.JFP-11-262

Del Rio, B., Binetti, A. G., Martin, M. C., Fernandez, M., Magadan, A. H., and Alvarez, M. A. (2007). Multiplex PCR for the detection and identification of dairy bacteriophages in milk. Food Microbiol. 24, 75-81. doi: 10.1016/j.fm.2006.03.001

Del Rio, B., Martin, M. C., Martinez, N., Magadan, A. H., and Alvarez, M. A. (2008). Multiplex fast real-time PCR for quantitative detection and identification of cos- and pac-type Streptococcus thermophilus bacteriophages. Appl. Environ. Microbiol. 74, 4779-4781. doi: 10.1128/AEM.00295-08

Deveau, H., Labrie, S. J., Chopin, M. C., and Moineau, S. (2006). Biodiversity and classification of lactococcal phages. Appl. Environ. Microbiol. 72, 4338-4346. doi: 10.1128/AEM.02517-05

Du, Y., Song, L., Feng, W., Pei, G., Zheng, P., Yu, Z., et al. (2013). Draft genome sequence of Lactococcus lactis subsp. lactis strain YF11. Genome Announc. 1. doi: 10.1128/genomeA.00599-13

Dupuis, M. E., and Moineau, S. (2010). Genome organization and characterization of the virulent lactococcal phage 1358 and its similarities to Listeria phages. Appl. Environ. Microbiol. 76, 1623-1632. doi: 10.1128/AEM.02173-09

Ehrmann, M. A., Angelov, A., Picozzi, C., Foschino, R., and Vogel, R. F. (2013). The genome of the Lactobacillus sanfranciscensis temperate phage EV3. BMC Res. Notes 6:514. doi: 10.1186/1756-0500-6-514

Eid, J., Fehr, A., Gray, J., Luong, K., Lyle, J., Otto, G., et al. (2009). Real-time DNA sequencing from single polymerase molecules. Science 323, 133-138. doi: 10.1126/science. 1162986

Felis, G. E., and Dellaglio, F. (2007). Taxonomy of Lactobacilli and Bifidobacteria. Curr. Issues Intest. Microbiol. 8, 44-61.

Fortier, L. C., Bransi, A., and Moineau, S. (2006). Genome sequence and global gene expression of Q54, a new phage species linking the 936 and c2 phage species of Lactococcus lactis. J. Bacteriol. 188, 6101-6114. doi: 10.1128/JB.00581-06

Foschino, R., Venturelli, E., and Picozzi, C. (2005). Isolation and characterization of a virulent Lactobacillus sanfranciscensis bacteriophage and its impact on microbial population in sourdough. Curr. Microbiol. 51, 413-418. doi: 10.1007/s00284-005-0122-y

Garneau, J. E., Tremblay, D. M., and Moineau, S. (2008). Characterization of 1706, a virulent phage from Lactococcus lactis with similarities to prophages from other Firmicutes. Virology 373, 298-309. doi: 10.1016/j.virol.2007.12.002

Gindreau, E., Torlois, S., and Lonvaud-Funel, A. (1997). Identification and sequence analysis of the region encoding the site-specific integration system from Leuconostoc oenos (Oenococcus oeni) temperate bacteriophage phi 10MC. FEMS Microbiol. Lett. 147, 279-285. doi: 10.1016/S0378-1097(96) 00540-X

Greer, G. G., Dilts, B. D., and Ackermann, H. W. (2007). Characterization of a Leuconostoc gelidum bacteriophage from pork. Int. J. Food Microbiol. 114, 370-375. doi: 10.1016/j.ijfoodmicro.2006.09.021

Guglielmotti, D. M., Deveau, H., Binetti, A. G., Reinheimer, J. A., Moineau, S., and Quiberoni, A. (2009). Genome analysis of two virulent Streptococcus thermophilus phages isolated in Argentina. Int. J. Food Microbiol. 136, 101-109. doi: 10.1016/j.ijfoodmicro.2009.09.005

Jang, S. H., Yoon, B. H., and Chang, H. I. (2011). Complete nucleotide sequence of the temperate bacteriophage LBR48, a new member of the family Myoviridae. Arch. Virol. 156, 319-322. doi: 10.1007/s00705-010-0841-7

Jarvis, A. W. (1984). Differentiation of lactic streptococcal phages into phage species by DNA-DNA homology. Appl. Environ. Microbiol. 47, 343-349.

Jarvis, A. W., Fitzgerald, G. F., Mata, M., Mercenier, A., Neve, H., Powell, I. B., et al. (1991). Species and type phages of lactococcal bacteriophages. Intervirology 32, 2-9.

Johansen, E., and Kibenich, A. (1992). Characterization of Leuconostoc isolates from commercial mixed strain mesophilic starter cultures. J. Dairy Sci. 75, 1186-1191. doi: 10.3168/jds.S0022-0302(92)77865-5

Kleppen, H. P., Nes, I. F., and Holo, H. (2012). Characterization of a Leuconostoc bacteriophage infecting flavor producers of cheese starter cultures. Appl. Environ. Microbiol. 78, 6769-6772. doi: 10.1128/AEM.00562-12 
Kot, W., Hammer, K., Neve, H., and Vogensen, F. K. (2013). Identification of the receptor-binding protein in lytic Leuconostoc pseudomesenteroides bacteriophages. Appl. Environ. Microbiol. 79, 3311-3314. doi: 10.1128/AEM.00012-13

Kotsonis, S. E., Powell, I. B., Pillidge, C. J., Limsowtin, G. K., Hillier, A. J., and Davidson, B. E. (2008). Characterization and genomic analysis of phage asccphi28, a phage of the family Podoviridae infecting Lactococcus lactis. Appl. Environ. Microbiol. 74, 3453-3460. doi: 10.1128/AEM.02379-07

Labrie, S. J., and Moineau, S. (2007). Abortive infection mechanisms and prophage sequences significantly influence the genetic makeup of emerging lytic lactococcal phages. J. Bacteriol. 189, 1482-1487. doi: 10.1128/JB.01111-06

Labrie, S., and Moineau, S. (2000). Multiplex PCR for detection and identification of lactococcal bacteriophages. Appl. Environ. Microbiol. 66, 987-994. doi: 10.1128/AEM.66.3.987-994.2000

Labrie, S., and Moineau, S. (2002). Complete genomic sequence of bacteriophage ul36: demonstration of phage heterogeneity within the P335 quasi-species of lactococcal phages. Virology 296, 308-320. doi: 10.1006/viro.2002.1401

Lavigne, R., Darius, P., Summer, E. J., Seto, D., Mahadevan, P., Nilsson, A. S., et al. (2009). Classification of Myoviridae bacteriophages using protein sequence similarity. BMC Microbiol. 9:224. doi: 10.1186/1471-2180-9-224

Lavigne, R., Noben, J. P., Hertveldt, K., Ceyssens, P. J., Briers, Y., Dumont, D., et al. (2006). The structural proteome of Pseudomonas aeruginosa bacteriophage phiKMV. Microbiology 152, 529-534. doi: 10.1099/mic.0.28431-0

Le Marrec, C., Van Sinderen, D., Walsh, L., Stanley, E., Vlegels, E., Moineau, S., et al. (1997). Two groups of bacteriophages infecting Streptococcus thermophilus can be distinguished on the basis of mode of packaging and genetic determinants for major structural proteins. Appl. Environ. Microbiol. 63, 3246-3253.

Levesque, C., Duplessis, M., Labonte, J., Labrie, S., Fremaux, C., Tremblay, D., et al. (2005). Genomic organization and molecular analysis of virulent bacteriophage 2972 infecting an exopolysaccharide-producing Streptococcus thermophilus strain. Appl. Environ. Microbiol. 71, 4057-4068. doi: 10.1128/AEM.71.7.40574068.2005

Lu, Z., Altermann, E., Breidt, F., and Kozyavkin, S. (2010). Sequence analysis of Leuconostoc mesenteroides bacteriophage Phil-A4 isolated from an industrial vegetable fermentation. Appl. Environ. Microbiol. 76, 1955-1966. doi: 10.1128/AEM.02126-09

Lu, Z., Breidt, F., Plengvidhya, V., and Fleming, H. P. (2003). Bacteriophage ecology in commercial sauerkraut fermentations. Appl. Environ. Microbiol. 69, 3192-3202. doi: 10.1128/AEM.69.6.3192-3202.2003

Lu, Z., Perez-Diaz, I. M., Hayes, J. S., and Breidt, F. (2012). Bacteriophage ecology in a commercial cucumber fermentation. Appl. Environ. Microbiol. 78, 8571-8578. doi: 10.1128/AEM.01914-12

Lucchini, S., Desiere, F., and Brussow, H. (1999). Comparative genomics of Streptococcus thermophilus phage species supports a modular evolution theory. J. Virol. 73, 8647-8656.

Mahony, J., Ainsworth, S., Stockdale, S., and Van Sinderen, D. (2012a). Phages of lactic acid bacteria: the role of genetics in understanding phage-host interactions and their co-evolutionary processes. Virology 434, 143-150. doi: 10.1016/j.virol.2012.10.008

Mahony, J., Murphy, J., and Van Sinderen, D. (2012b). Lactococcal 936-type phages and dairy fermentation problems: from detection to evolution and prevention. Front. Microbiol. 3:335. doi: 10.3389/fmicb.2012.00335

Mahony, J., Deveau, H., McGrath, S., Ventura, M., Canchaya, C., Moineau, S., et al. (2006). Sequence and comparative genomic analysis of lactococcal bacteriophages jj50, 712 and P008: evolutionary insights into the 936 phage species. FEMS Microbiol. Lett. 261, 253-261. doi: 10.1111/j.1574-6968.2006. 00372.x

Mahony, J., Martel, B., Tremblay, D. M., Neve, H., Heller, K. J., Moineau, S., et al. (2013). Identification of a new P335 subgroup through molecular analysis of lactococcal phages Q33 and BM13. Appl. Environ. Microbiol. 79, 4401-4409. doi: 10.1128/AEM.00832-13

McGrath, S., Seegers, J. F., Fitzgerald, G. F., and Van Sinderen, D. (1999). Molecular characterization of a phage-encoded resistance system in Lactococcus lactis. Appl. Environ. Microbiol. 65, 1891-1899.

Meyer, M., and Kircher, M. (2010). Illumina sequencing library preparation for highly multiplexed target capture and sequencing. Cold Spring Harb. Protoc. 2010, pdb prot5448. doi: 10.1101/pdb.prot5448

Mills, S., Griffin, C., O’Sullivan, O., Coffey, A., McAuliffe, O. E., Meijer, W. C., et al. (2011). A new phage on the 'Mozzarella' block: bacteriophage 5093 shares a low level of homology with other Streptococcus thermophilus phages. Int. Dairy J. 21, 963-969. doi: 10.1016/j.idairyj.2011.06.003

Murphy, J., Royer, B., Mahony, J., Hoyles, L., Heller, K., Neve, H., et al. (2013). Biodiversity of lactococcal bacteriophages isolated from 3 Gouda-type cheese-producing plants. J. Dairy Sci. 96, 4945-4957. doi: 10.3168/jds.201 3-6748

Neve, H., Zenz, K. I., Desiere, F., Koch, A., Heller, K. J., and Brussow, H. (1998). Comparison of the lysogeny modules from the temperate Streptococcus thermophilus bacteriophages TP-J34 and Sfi21: implications for the modular theory of phage evolution. Virology 241, 61-72. doi: 10.1006/viro.199 7.8960

Nieto-Arribas, P., Sesena, S., Poveda, J. M., Palop, L., and Cabezas, L. (2010). Genotypic and technological characterization of Leuconostoc isolates to be used as adjunct starters in Manchego cheese manufacture. Food Microbiol. 27, 85-93. doi: 10.1016/j.fm.2009.08.006

Prevots, F., Mata, M., and Ritzenthaler, P. (1990). Taxonomic differentiation of 101 lactococcal bacteriophages and characterization of bacteriophages with unusually large genomes. Appl. Environ. Microbiol. 56, 2180-2185.

Proux, C., Van Sinderen, D., Suarez, J., Garcia, P., Ladero, V., Fitzgerald, G. F., et al. (2002). The dilemma of phage taxonomy illustrated by comparative genomics of Sfi21-like Siphoviridae in lactic acid bacteria. J. Bacteriol. 184, 6026-6036. doi: 10.1128/JB.184.21.6026-6036.2002

Quiberoni, A., Stiefel, J. I., and Reinheimer, J. A. (2000). Characterization of phage receptors in Streptococcus thermophilus using purified cell walls obtained by a simple protocol. J. Appl. Microbiol. 89, 1059-1065. doi: 10.1046/j.13652672.2000.01214.x

Rohwer, F., and Edwards, R. (2002). The phage proteomic tree: a genome-based taxonomy for phage. J. Bacteriol. 184, 4529-4535. doi: 10.1128/JB.184.16.45294535.2002

Ronaghi, M., Uhlen, M., and Nyren, P. (1998). A sequencing method based on realtime pyrophosphate. Science 281, 363-365. doi: 10.1126/science.281.5375.363

Rousseau, G. M., and Moineau, S. (2009). Evolution of Lactococcus lactis phages within a cheese factory. Appl. Environ. Microbiol. 75, 5336-5344. doi: 10.1128/AEM.00761-09

Samson, J. E., Magadan, A. H., Sabri, M., and Moineau, S. (2013). Revenge of the phages: defeating bacterial defences. Nat. Rev. Microbiol. 11, 675-687. doi: 10.1038/nrmicro3096

Samson, J. E., and Moineau, S. (2010). Characterization of Lactococcus lactis phage 949 and comparison with other lactococcal phages. Appl. Environ. Microbiol. 76, 6843-6852. doi: 10.1128/AEM.00796-10

Scaltriti, E., Moineau, S., Launay, H., Masson, J. Y., Rivetti, C., Ramoni, R., et al. (2010). Deciphering the function of lactococcal phage ul36 Sak domains. J. Struct. Biol. 170, 462-469. doi: 10.1016/j.jsb.2009.12.021

Siezen, R. J., Bayjanov, J., Renckens, B., Wels, M., Van Hijum, S. A., Molenaar, D., et al. (2010). Complete genome sequence of Lactococcus lactis subsp. lactis KF147, a plant-associated lactic acid bacterium. J. Bacteriol. 192, 2649-2650. doi: 10.1128/JB.00276-10

Sutherland, M., Van Vuuren, H. J., and Howe, M. M. (1994). Cloning, sequence and in vitro transcription/translation analysis of a 3.2-kb EcoRI-HindIII fragment of Leuconostoc oenos bacteriophage L10. Gene 148, 125-129. doi: 10.1016/03781119(94)90245-3

Veesler, D., Spinelli, S., Mahony, J., Lichiere, J., Blangy, S., Bricogne, G., et al. (2012). Structure of the phage TP901-1 1.8 MDa baseplate suggests an alternative host adhesion mechanism. Proc. Natl. Acad. Sci. U.S.A. 109, 8954-8958 doi: 10.1073/pnas.1200966109

Ventura, M., Zomer, A., Canchaya, C., O’Connell-Motherway, M., Kuipers, O., Turroni, F., et al. (2007). Comparative analyses of prophage-like elements present in two Lactococcus lactis strains. Appl. Environ. Microbiol. 73, 7771-7780. doi: 10.1128/AEM.01273-07

Villion, M., Chopin, M. C., Deveau, H., Ehrlich, S. D., Moineau, S., and Chopin, A. (2009). P087, a lactococcal phage with a morphogenesis module similar to an Enterococcus faecalis prophage. Virology 388, 49-56. doi: 10.1016/j.virol.2009.03.011

Villion, M., and Moineau, S. (2009). Bacteriophages of Lactobacillus. Front. Biosci. (Landmark Ed) 14, 1661-1683. doi: 10.2741/3332

Wegmann, U., O'Connell-Motherway, M., Zomer, A., Buist, G., Shearman, C., Canchaya, C., et al. (2007). Complete genome sequence of the prototype lactic acid bacterium Lactococcus lactis subsp. cremoris MG1363. J. Bacteriol. 189, 3256-3270. doi: 10.1128/JB.01768-06 
Yoon, B. H., and Chang, H. I. (2011). Complete genomic sequence of the Lactobacillus temperate phage LF1. Arch. Virol. 156, 1909-1912. doi: 10.1007/s00705-011-1082-0

Zago, M., Scaltriti, E., Rossetti, L., Guffanti, A., Armiento, A., Fornasari, M. E., et al. (2013). Characterization of the genome of the dairy Lactobacillus helveticus bacteriophage $\{$ Phi\}AQ113. Appl. Environ. Microbiol. 79, 4712-4718. doi: 10.1128/AEM.00620-13

Zamfir, M., Vancanneyt, M., Makras, L., Vaningelgem, F., Lefebvre, K., Pot, B., et al. (2006). Biodiversity of lactic acid bacteria in Romanian dairy products. Syst. Appl. Microbiol. 29, 487-495. doi: 10.1016/j.syapm.2005.10.002

Zhang, X., Wang, S., Guo, T., and Kong, J. (2011). Genome analysis of Lactobacillus fermentum temperate bacteriophage, PYB5. Int. J. Food Microbiol. 144, 400-405. doi: 10.1016/j.ijfoodmicro.2010.10.026

Zinno, P., Janzen, T., Bennedsen, M., Ercolini, D., and Mauriello, G. (2010). Characterization of Streptococcus thermophilus lytic bacteriophages from mozzarella cheese plants. Int. J. Food Microbiol. 138, 137-144. doi: 10.1016/j.ijfoodmicro.2009.12.008
Conflict of Interest Statement: The authors declare that the research was conducted in the absence of any commercial or financial relationships that could be construed as a potential conflict of interest.

Received: 02 December 2013; paper pending published: 22 December 2013; accepted: 07 January 2014; published online: 24 January 2014.

Citation: Mahony J and van Sinderen D (2014) Current taxonomy of phages infecting lactic acid bacteria. Front. Microbiol. 5:7. doi: 10.3389/fmicb.2014.00007

This article was submitted to Virology, a section of the journal Frontiers in Microbiology.

Copyright (C) 2014 Mahony and van Sinderen. This is an open-access article distributed under the terms of the Creative Commons Attribution License (CC BY). The use, distribution or reproduction in other forums is permitted, provided the original author(s) or licensor are credited and that the original publication in this journal is cited, in accordance with accepted academic practice. No use, distribution or reproduction is permitted which does not comply with these terms. 